\title{
Implementasi Sistem Siaran Televisi Digital di LPP TVRI Stasiun Jawa Tengah
}

\author{
Marwiyati ${ }^{1}$, Ade Wahyudin ${ }^{2}$ \\ ${ }^{1,2}$ Program Studi Manajemen Teknik Studio Produksi, Sekolah Tinggi Multi Media Yogyakarta \\ Jl. Magelang No.KM.6, Mlati, Sleman, D. I. Yogyakarta, Indonesia \\ Email: mmtc.marwi@gmail.com ${ }^{1 *}$ \\ *corresponding author
}

\begin{abstract}
The implementation of digital television broadcast system is not easy, there are some obstacles such as people's unpreparedness in adopting new systems, reception system infrastructure and television unit aircraft should be replaced, as well as adding Set Top Box equipment. The purpose of this research is to find out the implementation of a digital television broadcast system at LPP TVRI Central Java Station. This research uses qualitative descriptive methods, with observation and interview data collection techniques. The results of LPP TVRI research central Java station received infrastructure subsidy in the form of transmitters or digital transmissions in 2013 from menkominfo with UHF type BT-ESA (DVB-T2), brand hospital with radiance strength of $5 \mathrm{KW}$. LPP TVRI Central Java Station as an infrastructure provider in the digital television broadcast system is very supportive and has stated ready to switch to the digital system. The results of digital broadcast trials have not been able to reach all areas of Central Java, due to infrastructure and hr constrained. This is because there is no regulation or government policy from the legal umbrella, adequate infrastructure, public rights, and the price of expensive DVB-T2 television aircraft. This research provides recommendations to the government to provide subsidies to the procurement of digital TV setup boxes so that all regions in Central Java are affordable digital broadcasts, as well as provide training to human resources operating digital TV devices.
\end{abstract} Keywords: Digital Television; DVB-T2; Infrastructure; LPP TVRI Central Java Station; Set Top Box

\section{Abstrak}

Implementasi sistem siaran televisi digital tidaklah mudah, ada beberapa kendala seperti ketidaksiapan masyarakat dalam mengadopsi sistem baru, infrastruktur sistem penerimaan dan pesawat unit televisi harus diganti, serta menambah peralatan Set Top Box. Tujuan penelitian ini untuk mengetahui implementasi sistem siaran televisi digital di LPPTVRI Stasiun Jawa Tengah. Penelitian ini menggunakan metode deskriptifkualitatif, dengan teknik pengumpulan data observasi dan wawancara. Hasil penelitian LPP TVRI Stasiun Jawa Tengah mendapatkan subsidi infrastruktur yang berupa pemancar atau transmisi digital pada tahun 2013 dari Menkominfo dengan type UHF BT-ESA(DVB-T2), Merk RS dengan kekuatan pancar 5 KW. LPP TVRI Stasiun Jawa Tengah sebagai penyedia infrastruktur dalam sistem siaran televisi digital sangat mendukung dan sudah menyatakan siap untuk beralih ke sistem digital. Hasil uji coba siaran digital belum bisa menjangkau semua wilayah masyarakat Jawa Tengah, karena terkendala infrastruktur dan SDM. Hal tersebut disebabkan karena belum ada regulasi atau kebijakan pemerintah dari payung hukum, infrastruktur yang memadai, hak publik, dan harga pesawat televisi berformat DVB-T2 yang mahal. Penelitian ini memberikan rekomendasi kepada pemerintah untuk memberikan subsidi terhadap pengadaan setup box TV digital agar seluruh daerah di Jawa Tengah terjangkau siaran digital, serta memberikan pelatihan kepada SDM yang mengoperasikan perangkat TV digital. Kata kunci: Televisi Digital; DVB-T2; Insfrastruktur; LPP TVRI Stasiun Jawa Tengah; Set Top Box

\section{Pendahuluan}

Pemerintah Indonesia menetapkan tahun 2014 sudah beralih ke televisi digital dan tahun 2017 seluruh Indonesia sudah bermigrasi ke sistem digital. Keberadaan teknologi ini dengan diterbitkannya Peraturan Menteri No.07/P/PM/ KOMINFO/3/2007 tentang Standar Penyiaran Digital Teresterial untuk televisi tidak bergerak di Indonesia, guna mengantisipasi proses migrasi dari sistem analog ke digital (Susanto et al., 2016), Proses migrasi siaran televisi digital Indonesia dengan daya pancar lima (5) kilowatt merupakan titik awal Kementerian Komunikasi dan Informati di tahun 2009 di Jabodetabek. Proses migrasi ini menjanjikan keuntungan tidak hanya bagi penyelenggara industri siaran, tetapi 
juga masyarakat luas sebagai pengguna atau penikmat siaran televisi digital. Keuntungan yang diperoleh, antara lain: kualitas audio dan video yang lebih baik, resiko terjadinya interferensi atau gangguan dapat diperkecil, banyak variatif program yang ditawarkan, terbukanya peluang bisnis di bidang penyiaran baik peralatan, serta software dan konten yang satu frekuensi dapat digunakan untuk 6-8 kannal transmisi dengan program yang berbeda melalui penerapan sistem multiplexing (Ariansyah, 2014).

Lapangan main televisi digital dapat dipetakan ke dalam tiga bagian, yaitu televisi digital, kompunen dan unsur pendukung, serta pemain pendukung. Unsur pendukung televisi digital terdiri dari aturan main, teknologi, pengguna, penyelenggara, serta hardware dan software. Sektor pendukung terdiri dari pemerintah, peneliti, pemirsa televisi, industry dan penyelenggara multiplexing, program siaran serta penyedia konten sehingga dalam implementasi televisi digital, peran penting tidak hanya dipegang oleh pemerintah akan tetapi juga oleh pemain pendukung dan komponen pendukunglainnya(Gultom,2015;Gultom,2018).

Progres implementasi beberapa peraturan telah diterbitkan diantaranya peraturan Menkominfo No.22/2011 tentang Penyelenggara Penyiaran Televisi Digital Teresterial Penerimaan tetap tidak Berbayar (Free to Air) dan No. 23/2011 tentang Rencana Induk (Master Plan) Frekuensi Rasio untuk keperluan Sistem Siaran Televisi Digital Terrestial pada Pita Frekuensi Radio 478-694 MHz (Munadi et al., 2016). Implementasi perpindahan televisi analog ke digital tidaklah mudah, sebab masih ada beberapa kendala yang harus diselesaikan terlebih dahulu, seperti masyarakat sebagai pengguna atau penikmat siaran televisi lebih pada kesiapan dalam mengadopsi sistem baru, insfrastruktur sistem penerimaan disisi pengguna, dalam hal ini masyarakat akan mengalami perubahan, televisi harus dapat menerima siaran digital sehingga muncul dua pilihan, mengganti unit televisi atau menambahkan perangkat Set Top Box (STB) pada unit televisi dan sosialisasi kemasyarakat belum sampai kekampung kampung sehingga belum paham untuk digitalisasi.

Pada penelitian oleh Wahyudin dan Sakinah (2017) mengenai perancangan dan analisa penggelaran Lte pada frekuensi $700 \mathrm{Mhz}$ dengan metode adaptif modulation coding untuk implementasi digital dividend di wilayah sub-urban dan rural kabupaten banyumas menjelaskan bahwa keuntungan utama dari penyiaran digital adalah pemanfaatan spectrum frekuensi yang lebih efisien, terutama dalam penggunaan pita frekuensi yang saat ini dipakai oleh TV Analog yaitu pada jangkauan frekuensi $694-820 \mathrm{MHz}$. Proses migrasi TV Analog menuju TV Digital (Analog to Digital Switchover) memberikan peluang yang sangat menjanjikan bagi operator telekomunikasi untuk menggunakan frekuensi $700 \mathrm{MHz}$ sebagai frekuensi kerja LTE. Hal ini dikarenakan, salah satu keuntungan dari penggunaan frekuensi 700 $\mathrm{MHz}$ tersebut yaitu radius sel yang lebih luas, sehingga diharapkan mampu meningkatkan penetrasi ICT ke wilayah rural dan terpencil di Indonesia atau disebut skema Digital Devidend.

Penelitian yang dilakukan oleh Gultom (2018) mengenai Digitalisasi Penyiaran Televisi di Indonesia Digitization" pada jurnal Buletin Pos dan Telekomunikasi menjelaskan bahwa Indonesia menghadapi beberapa tantangan yang timbul dalam peralihan ke penyiaran digital. Di sisi regulasi, UU Penyiaran saat ini belum mengatur penyiaran digital secara spesifik.Perlu segera disahkan UU Penyiaran yang baru agar dapat mengakomodasi regulasi terkait penyiaran digital.Permasalahan hukum terkait regulasi penyiaran digital berdampak tenggat waktu peralihan dari analog ke penyiaran televisi digital tahun 2018 yang tidak dapat dipenuhi. Di sisi konsumen, untuk dapat mendapatkan layanan televisi digital di televisi analog yang diwajibkan untuk memiliki dekoder. Untuk jadi perhatian pemerintah terkait penyediaan dekoder agar mudah diperoleh. 


\section{Sistem Siaran Digital Televisi}

Televisi digital atau DTV merupakan jenis televisi yang menggunakan modulasi digital dan sistem kompresi untuk menyiarkan sinyal gambar, suara, dan data ke pesawat televisi. Televisi digital merupakan alat yang digunakan untuk menangkap siaran televisi digital, perkembangan dari sistem analog ke digital yang mengubah informasi menjadi sinyal digital berbentuk bit data seperti komputer (Nuryanto, 2014).

Infiltrasi teknologi digital memang tak bisa dihindari, tidak terkecualijuga di dunia broadcast. Teknologi digital sudah sejak dulu digunakan misalnya peralatan seperti: video mixer, standart conventer, character generator, still store dan komputer grafik semuanya ini adalah peralatan standart broadcast berteknologi digital yang sejak dulu sudah digunakan sebagai sarana produksi untuk siaran televisi (Sari, 2015). Justru satu-satunya peralatan siaran yang masih analog adalah pemancarnya, jika pemancar ini diganti dengan pemancar digital maka semua peralatan siaran televisi benar-benar $100 \%$ digital. Penggantian pemancar menjadi digital tidak berpengaruh pada peralatan produksi maupun pasca produksi, karena semua peralatan lebih dulu bermigrasi ke digital. Alasan utama penggantian pemancar digital adalah demi efisiensi pemakaian spectrum frekuensi, karena frekuensi sumber daya alam yang tidak bisa diperbaruhi, sehingga keberadaannya harus dimanfaatkan seefisien mungkin. Satu-satunya cara yang mampu meningkatkan efisiensi pemakaian frekuensi ini adalah teknologi digital (Budiman, 2015).

Di Indonesia alokasi frekuensi untuk siaran televisi berada pada band UHF dengan rentang frekuensi mulai dari 478 - $806 \mathrm{MHz}$ untuk kanal siarantelevisianalog. Jadidalam rentang frekuensi itu seharusnya ada 40 kanal yang bisa digunakan, tetapi kenyataanya hanya 20 kanal saja yang bisa dimanfaatkan karena kanal yang bersebelahan ini saling mengganggu. Hal ini terlihat jelas bahwa betapa borosnya pemakaian frekuensi pemancar analog, sebab dibutuhkan hanya $8 \mathrm{MHz}$ lagi untuk dikosongkan. Hal ini menyebabkan banyak calon penyelenggara siaran televisi tidak kebagian frekuensi. Pemerintah pun tidak bisa berbuat apa-apa untuk melayani permintaan itu karena memang sudah tidak ada slot lagi frekuensi yang bisa diberikan (Setiawan, 2013).

Teknologi pemancar digital dinilai mampu mengatasi persoalan pemborosan frekuensi dan terbukti mampu menghemat bandwith secara besar-besaran. Penggunaan teknologi digital ini tidak ada lagi masalah adjacent channel artinya dari 40 kanal yang tersedia, semuanya bisa diduduki. Satu pemancar televisi digital yang butuh $8 \mathrm{MHz}$ untuk beroperasi, hanya $8 \mathrm{Mhz}$ itulah yang bisa diduduki. Kanal disebelahnya (adjascent channel) bisa diduduki oleh pemancar televise digital tanpa keduanya saling mengganggu (Widjojo, 2013).

Teknologi digital (DVB-T2) bisa menyiarkan 12 program sekaligus, jika ada 40 kanal yang tersedia, maka dengan dapat menyiarkan 480 program yang berbeda secara bersamaan. Jumlah program 480 dinilai terlalu berlebihan sehingga pemerintah melalui Permen Kominfo No.23 Tahun 2011 telah menetapkan hanya 27 kanal saja yang dialokasi untuk siaran televisi digital, sedangkan 13 kanal sisanya akan dialokasikan untuk keperluan lain.

Pemerintah Indonesia melalui Permen Kominfo No.5 Tahun2012 telah menetapkan DVB-T2 (Digital Video BroadcastingTeresterial 2 Generation) sebagai satu-satunya standart yang berlaku untuk siaran TV digital di Indonesia. Pemilihan standart ini didasarkan atas hasil penelitian bahwa DVB-T2 adalah teknologi yang berkecepatan data yang paling mendekati garis "Shannon Limit" yaitu suatu garis mendekati batas maximal kecepatan pengirim data dengan faktor kesalahan mendekati nol (error free maximum data speed) (Digital Terrestrial Television Action Group, 2009).

Sistem siaran digital juga menghemat bandwith, transmisi digital sangat kebal terhadap gangguan atau noise. Hal ini 
disebabkan karena pesawat penerima hanya diperintahkan untuk mengenali dua kondisi saja, yaitu " 1 " dan " 0 ". Analoginya mirip dengan mata manusia yang lebih mudah mengenali lampu yang berkedip dibandingkan lampu yang menyala tetapi terangnya berubah-ubah (analog). Lampu yang berkedip membuat mata lebih peka dalam mengenali lampu itu sedang menyala atau mati. Kecil kemungkinan bagi mata untuk salah menerima informasi bahwa lampu itu sedang menyala atau mati.

Di dalam transmisi sistem televisi digital selalu dilengkapi dengan sebuah sistem yang mampu memperbaiki kesalahan pengiriman data akibat gangguan atau noise yang disebut dengan FEC (Forward Error Correction). Fungsi FEC yaitu menerima informasi menjadi utuh kembali (error free), karena setiap kali ada kesalahan secara otomatis langsung dikoreksi. Itulah sebabnya dengan transmisi digital, gambar dan suara yang diterima kualitasnya sama dengan gambar dan suara yang dikirim dari studio (Wahyudin \& Sakinah, 2017).

\section{Set Top Box}

Set Top Box (STB) merupakan sebuah perangkat yang mengkonversi sinyal digital kembali ke analog, sehingga dapat menyaksikan TV free-to-air digital pada perangkat TV analog. Set Top Box bertindak sebagai perangkat yang berhubungan secara fisik dengan televisi sehingga memungkinkan pengguna televisi untuk dapat menikmati layanan tambahan selain itu menerima perintah dari pengguna, seperti penggunaan remote atau tombol papan ketik, dan mengirim perintah-perintah ini kembali ke perangkat.

Prinsip kerja Set Top Box sebenarnya mirip dengan penerima televisi biasa yang sudah terdapat pada televisi analog, namun Set Top Box berguna untuk mengubah sinyal digital yang diterima dari satelit, kabel, ataupun internet ke dalam format analog agar dapat ditampilkan ke layar televisi analog atau perangkat layar analog lainnya. Set Top Box biasanya digunakan di sistem TV kabel. TV satelit, Ip-TV, maupun TV digital teresterial. Keberadaan saluran televisi merupakan kebijakan dari penyedia layanan televisi berbayar, yang bisa saja berbeda antara satu dengan yang lainnya. Set Top Box juga memiliki prosesor mikro, memori RAM, MPEG-2 decoder chip, serta chip-chip lain yang berguna dalam pemrosesan data audio maupun data visual (Jamroni, 2010).

\section{Sistem Transmisi atau Pemancar Digital}

DM4100A Exciter mengubah sinyalsinyal input, DVB-ASI, ke sinyal RF yang termodulasi oleh OFDM yang berfungsi untuk mengamplifikasikan akhir pada sistem pemancar/transmisi DTV. Fungsi exciter untuk pengkodean sinyal TS untuk modulasi OFDM, mengubah sinyal baseband menjadi frekuensi RF dan memperbaiki sinyal awal untuk mengkompensasi distorsi yang dihasilkan pada penguat daya tinggi, dan exciter mengatur waktu pengalihan sinyal berdasarkan referensi dan informasi control (Prasetyo, 2013).

\section{Metode Penelitian}

Penelitian ini menggunakan pendekatan deskriptif kualitatif, dimana dilakukan dengan pendekatan studi kasus di LPP TVRI Stasiun Jawa Tengah. Data penelitian didapatkan dengan melakukan observasi secara langsung terhadap LPP TVRI Stasiun Jawa Tengah dan wawancara dengan pihak yang terkait dengan pelaksanaan TV Digital. Materi data yang dibahas meliputi kemajuan implementasi penyiaran TV digital, kebijakan, strategi dan teknologi TV digital. Wawancara dilakukan dengan memilih sample yang bersifat selektif yaitu informan yang di pandang paling tahu, sehingga kemungkinan pilihan informan dapat berkembang sesuai dengan kebutuhan dan kemantapan penulis yang penulis ajukan (Sugiyono, 2017). Adapun informan tersebut adalah, Kepala Seksi Transmisi, karyawan, staf transmisi dan perwakilan masyarakat Jawa 
Tengah. Selain itu, data didapatkan dari arsip dan dokumen resmi serta buku-buku yang sesuai dengan implementasi sistem siaran digital.

Teknik analisis data dilakukan dengan pengumpulan data di lapangan dengan melakukan wawancara mendalam dengan informan yaitu dengan pihak pembimbing penelitian yang berkaitan dengan permasalahan. Hasil wawancara data sekunder dan studi pustaka dianalisis dengan analisis perbandingan yang merupakan salah satu metode analisa data kualitatif. Dalam mengajukan pertanyaan lebih mendalam dan dilengkapi dengan melakukan refleksi pada hasil diskripsi data informan sebelumnya, membuat catatan kecil dan setelah wawancara dibuat deskripsi lengkap lalu dilakukan refleksi. Demikian seterusnya hingga data lengkap kemudian dilakukan reduksi data yang dipisah-pisah berdasarkan kelompok-kelompok kebutuhan data sesuai penelitian, data tersebut diolah menjadi hasil penelitian yang disajikan dalam bentuk gambar dan deskripsi untuk menarik kesimpulan penelitian ini (Sugiyono, 2008).

\section{Hasil dan Pembahasan \\ Regulasi dan Kebijakan Siaran Televisi Digital}

Kebijakan digitalisasi penyiaran dipandang sebagai peluang untuk memperluas dan mengembangkan jangkauan jenis-jenis layanan penyiaran yang dapat disediakan bagi para penonton. Mendesaknya agenda digitalisasi karena siaran analog dinilai sudah tidak lagi sejalan dengan kemajuan zaman yang serba sempurna, ringkas dan jelas sehingga diperlukan migrasi sistem. Migrasi sistem siaran analog ke digital dilakukan dalam 3 tahap yang telah ditetapkan oleh pemerintah, yaitu: 1) Tahap I tahun 2008-2012 meliputi perizinan penyiaran analog, pengenalan sistem siaran televisi digital, periode simulcast; 2) Tahap II tahun 2017 seluruh penyiaran sistem analog pindah ke sistem televisi digital khususnya dikota besar dan beberapa daerah pilihan; dan 3) Tahap III tahun 2017 seluruh penyiaran telah migrasi ke sistem siaran televisi digital (cut off analog). Hal selanjutnya, pemerintah membentuk dua (2) kelembagaan sistem siaran, yaitu: 1) Penyedia Infrastruktur (Network Provider) yang merupakan lembaga atau perusahaan yang diberikan izin untuk menyediakan Perangkat keras dan jaringan digital; 2) Penyedia Program (Content Provider) diberikan izin menyiarkan siarannya melalui program yang disediakan oleh penyelenggara infrastruktur.

LPPTVRIStasiun Jawa Tengah mendapatkan subsidi infrastruktur yang berupa pemancar transmisidigitalpadatahun2013 dariMenkominfo dengan type UHF BT-ESA (DVB-T2), Merk RS dengan kekuatan pancar $5 \mathrm{KW}$. Penggantian transmisi analog ke digital memiliki alasan, yaitu efisiensi pemakaian spectrum frekuensi, mampu menghemat bandwith, kebal terhadap gangguanatau noise dan dilengkapi sistem yang mampu memperbaiki kesalahan pengiriman data akibat gangguan noise yang disebut FEC (Forwart Error Corection) sehingga informasi yang diterima utuh kembali (error free). Pada tahun 2014 kebijakan pemerintah dalam mensukseskan sistem siaran televisi digital melalui TVRI Stasiun Jawa Tengah memberikan bantuan subsidi Set Top Box (STB) ke pada masyarakat Jawa Tengah dengan jumlah 300 buah yang didistribusikan ke masyarakat sekitar Stasiun TVRI Jawa Tengah dan belum bisa sampai ke wilayah masyarakat yang lebih luas.

\section{Teknologi sistem siaran televisi digital}

Di era analog penyedia infrastruktur dan program siaran dilakukan oleh satu lembaga penyiaran untuk menyiarkan satu program. Di era digital dengan teknologi terkini DVB-T2, penyedia infrastruktur oleh lembaga penyiaran bisa menyalurkan sampai 12 program siaran. Di era digital Lembaga Penyiaran Penyelenggara Program Siaran (LPS3) dalam menyalurkan 
program siarannya tidak perlu membangun atau memiliki infrastruktur sendiri, namun bisa menyewa dari Lembaga Penyiaran Multilexing (LP3M) sebagai infrastruktur. Infrastruktur televisi digital lebih mahal dibandingkan dengan infrastruktur televisi analog, membutuhkan investasi yang besar, sarana prasarana pembelian pemancar digital maupun proses membangun TX.

LPP TVRI Stasiun Jawa Tengah sebagai penyedia infrastruktur sistem siaran televisi digital sangat mendukung dan sudah menyatakan siap untuk beralih ke sistem digital dan sudah melakukan siaran uji coba siaran televisi digital. Uji coba sistem siaran televisi digital LPP TVRI stasiun Jawa Tengah dimulai pada pada bulan Januari tahun 2014 dengan kanal 28 UHF yang diikuti 3 (tiga) Lembaga Penyiaran Swasta (LPS) yang bergabung dalam 1 (satu) Multiplexer antara lain Nusantara TV, Net TV dan Inspira TV, namun masih ada kanal yang kosong dalam Mux. Sistem siaran simulcast atau simultan tetap dibutuhkan terutama di TVRI Jawa Tengah. Dua siaran baik analog dan digital beroperasi secara bersamaan bertujuan untuk menggiring pelanggan sehingga memilih layanan televisi digital dengan pertimbangan kualitas layanan yang lebih baik dibandingkan televisi analog yang bertujuan untuk memberikan tenggang waktu kepada pelanggan sebelum dilakukan Analog Switch Off (ASO). Program siaran televisi digital di mulai pada jam 19.00 sampai dengan jam 21.58 yang disiarkan di LPP TVRI Stasiun Jawa Tengah sebagai penyedia konten siaran dengan sistem siaran playback yang diperoleh dari program siaran analog yang sudah disiarkan yang lalu atau dengan ambil konten siaran yang berasal dari internet (down load). Implementasi sistem siaran televisi digital dari segi masa transisi analog ke digital bagi masyarakat khususnya Jawa Tengah baru sebagian kecil (38\%) yang bisa menerima siaran digital (pesawat penerima televisi yang berformat DVB-T2). Jangkauan sistem siaran televisi digital di LPP TVRI Stasiun Jawa Tengah meliputi: Semarang Kota, Kabupaten Semarang, Kudus, Kendal, Demak, Solotigo dan Pati.

\section{Sumber Daya Manusia (SDM) dalam siaran televisi digital}

Sumber Daya Manusia di TVRI Stasiun Jawa Tengah khususnya yang berkaitan operasional siaran televisi digital yang berjumlah enam orang sudah memperoleh pelatihan dalam hal sistem siaran televisi digital yang dilaksanakan di Balai Diklat TVRI Pusat Jakarta maupun di Perancis. Operasional sistem siaran televisi digital khususnya SDM bagian transmisi setiap harinya membuat play list siaran sendiri tidak melalui program perencanaan siaran dari sistem analog yang di mulai dari jam 19.00-21.58. Adapun program dan konten siarannya diambil dari beberapa TVRI seperti Negeri Indonesia TVRI Jabar, Saba Desa TVRI Jogja, Koes Mania, Seni Budaya Tradisional Wayang Kulit, Hymne Rayuan Pulau Kelapa selain itu materi siaran digital juga mengambil siaran analog yang sudah disiarkan ataupun dari internet.

\section{Kendala Sistem Siaran Televisi Digital}

LPP TVRI Stasiun Jawa Tengah memang sudah menyatakan siap dan mendukung adannya sistem siaran digital walaupun terkendala pada ketidakjelasan regulasi mulai dari payung hukum, infrastruktur, hingga hak publik. Dikeluarkannya Peraturan Menteri Komunikasi dan Informatika Nomor 31 Tahun 2014 tentang Rencana Induk (Master Plan) Frekuensi Radio Penyelenggara Telekomunikasi khusus untuk keperluan Televisi Siaran Analog Pada Pita Ultra High Frequency. Frequency perlu mendapatkan perhatian yang serius.

Uji coba sistem siaran televisi digital khususnya LPP TVRI Stasiun Jawa Tengah yang berkaitan dengan jangkauan siaran belum bisa melayani $70 \%$ dari masyarakat Jawa tengah dengan luas $32.548 \mathrm{Km}^{2}$ (baru $38 \%$ ) karena keterbatasan anggaran dan tidak mampu membangun pemancar di wilayah selatan akibatnya daerah Solo, Magelang, Wonogiri, Sukoharjo, Purworejo dan sekitarnya belum bisa menerima siaran digital. Kondisi ini jelas 
mempengaruhi pada kesiapan pelaksanaan implementasi sistem siaran televisi digitalisasi. LPP TVRI Stasiun Jawa Tengah sebagai penyedia konten siaran digital yang ikut multiplexer baru terdapat 3 (tiga) Lembaga Penyiaran Swasta dan masih ada kanal yang kosong, sehingga siapa yang mengisi kanal tersebut.

Sisi konten siaran televisi digital terlihat masih dalam bentuk playback yang diambil dari sistem analog atau dari internet karena memang tidak tersedianya anggaran sehingga hanya untuk mengisi siaran digital agar tetap berjalan. Implementasi sistem siaran siaran digital dari segi masa transisi analog ke digital bagi masyarakat khususnya Jawa Tengah belum maksimal terkendala mahalnya harga pesawat televisi berformat DVB-T2, pesawat penerima televisi digital juga masih banyak yang analog sehingga belum bisa menerima televisi digital masih membutuhkan peralatan tambahan yaitu Set Top Box (STB). Sosialisasi siaran televisi digital belum sampai ke pelosok-pelosok Jawa Tengah, sehingga masyarakat kurang mengetahui jenis siaran digital dan keuntungan, walaupun sudah mensosialisasikan lewat iklan yang berada di TVRI Pusat Jakarta dalam siaran Nasional.

\section{Sistem Siaran Televisi DVB T2 LPP TVRI Stasiun Jawa Tengah}

Teknologi digital tidak dapat dihindari walaupun di dunia broadcast, karena teknologi digital sejak dulu digunakan dan sudah peralatan standar broadcast berteknologi digital. Peralatan tersebut sudah digunakan sebagai sarana produksi untuk siaran televisi walaupun hanya untuk memperkaya tampilan sinyal video analog.

Penggantian peralatan dari pemancar analog ke pemancar digital memang cukup mahal, tetapi untuk peralatan pendukung tidak harus mengganti peralatan yang baru, karena masih dapat digunakan dan dimanfaatkan dari peralatan dari sistem analog seperti encoder, decoder, multiplexer yang harganya terjangkau bagi kelembagaan. Penambahan peralatan merupakan konsekuensi logis dari banyaknya program yang disiarkan secara bersama.

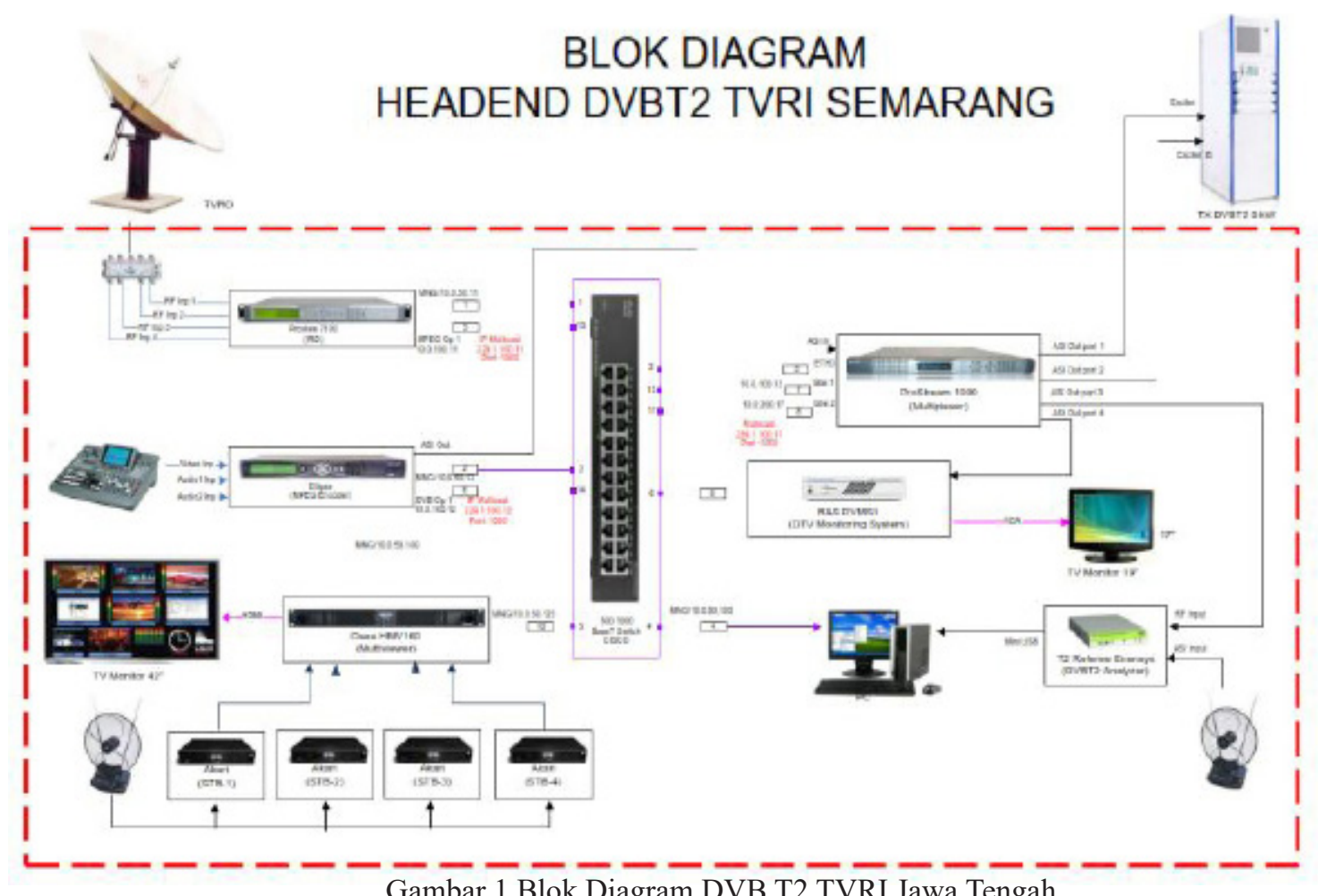

Sumber: LPP TVRI Jawa Tengah (2017) 
Gambar 1 memperlihatkan sistem siaran televisi DVB T2 di LPP TVRI Jawa Tengah.

Stasiun transmisi TVRI Gombel Semarang Jawa Tengah menggunakan Television Receiver Only (TVRO), yaitu antena parabola yang menangkap siaran pusat dari Jakarta lalu ditransmisikan ke daerah sekitar. Siaran berupa Radio Frekuensi (RF) diterima modul Integreted Receiver Decoder (IRD) Proview 7100 yang bertugas melakukan proses decoding menuju transport stream. Modul Head End yang selain jaringan ASI dihubungkan menggunakan Base T Switch agar perangkat transmisi dapat saling terkoneksi satu dengan yang lain. Sinyal audio dan video analog yang masuk akan diolah menggunakan mixer selanjutnya menuju ke modul MPEG Encoder untuk memproses sinyal audio dan video yang masih analog menjadi sinyal digital selanjutnya data di kirim ke modul multiplexer Pro Stream 1000 yang berfungsi menggabungkan masing-masing paket data program siaran menjadi satu paket data tunggal.

Output pada modul ini menuju beberapa port antara lain ASI Out Port 1 dan ASI Out Port 2 menuju ke exciter yang berfungsi sebagai pemancar DVB-T2 dengan output $5 \mathrm{Kw}$. ASI Port 3 ketika diprogram menjadi output menuju DVB-T2 Analyzer untuk dianalisis kualitas sinyalnya ke dalam format DVB menggunakan modulasi OFDM, kemudian dari DVB-T2 analyzer dihubungkan ke PC. ASI Port 4 di program menjadi output menuju ke DVB-T2 secara bersamaan dapat memantau RF dan transportasi aliran karakteristik hingga empat sinyal yang dapat dipantau dengan menggunakan TV monitor.

Modul Multiviewer berfungsi sebagai pengolah gambar resolusi tinggi yang dapat dipantau oleh TV monitor 42. Modul ini mendapat input dari Set Top Box yang berfungsi sebagai penerima siaran digital yang mengkonversi sinyal digital agar dapat diterima oleh TV analog.

\section{Simpulan}

LPP TVRI Stasiun Jawa Tengah sebagai penyedia infrastruktur dalam implementasi sistem siaran digital sangat mendukung dan sudah menyatakan siap untuk beralih kesistem digital walaupun terdapat ketidakjelasan regulasi dan kebijakan pemerintah dari payung hukum, infrastruktur, hingga hak publik. Kebijakan pemerintah juga sering berubah seiring pergantian jabatan kelembagaan.

Uji coba sistem siaran televisi digital khususnya yang berkaitan dengan jangkauan siaran belum bisa melayani $70 \%$ dari masyarakat Jawa Tengah dengan luas $32.548 \mathrm{Km}^{2}$ (baru $38 \%$ ), karena keterbatasan anggaran dan tidak mampu membangun pemancar di wilayah selatan. Hal ini berdampak di daerah Solo, Magelang, Wonogiri, Sukoharjo, Purworejo dan sekitarnya belum bisa menerima siaran digital. Subsidi dari pemerintah hanya mendapatkan satu (1) buah pemancar digital yang dipasang di daerah bukit Gombel. Segi konten siaran televisi digital masih dalam bentuk playback yang diambil dari sistem analog atau dari internet karena memang tidak tersedianya anggaran sehingga hanya untuk mengisi siaran digital agar tetap berjalan.

Masyarakat khususnya Jawa Tengah belum maksimal dalam menerima siaran digital terkendala mahalnya harga pesawat televisi berformat DVB-T2, pesawat penerima televisi digital juga masih banyak yang analog sehingga belum bisa menerima televisi digital masih membutuhkan peralatan tambahan yaitu Set Top Box (STB). Sosialisasi siaran televisi digital belum sampai ke pelosok-pelosok Jawa Tengah sehingga masyarakat kurang mengetahui apa siaran digital dan keuntungannya walaupun sudah mensosialisasikan lewat iklan yang berada di TVRI Pusat Jakarta dalam siaran Nasional.

Implementasi regulasi dan kebijakan digitalisasi penyiaran TVRI harus segera dipastikan sejalan tugas pokoknya sebagai Lembaga Penyiaran Publik, walaupun belum ada undang-undang sebagai landasan hukum yang 
melingkupinya. Pemerintah perlu memberikan penambahan subsidi pemancar digital, agar masyarakat bisa menikmati dan menerima siaran digital khususnya wilayah Solo, Magelang, Purworejo, Sukoharjo, Wonogiri dan sekitarnya sehingga implementasi sistem siaran televisi digital segera terwujud. Pemerintah lebih antosias dalam mensosialisasikan ke lembaga lembaga penyiaran swasta agar mau bergabung dalam MUX yang berada di TVRI Jawa Tengah agar kanal frekuensi dapat terisi penuh. Sistem siaran televisi digital membutuhkan konten siaran dan program yang banyak karena dalam satu kanal bisa menampilkan 5 sampai dengan 12 konten yang berbeda dan disiarkan secara bersama sehingga sangat dibutuhkan penambahan anggaran. Penggunaan konten siaran yang menarik diharapkan masyarakat secara perlahan lahan perpindah ke sistem digital. Implementasi siaran televisi digital cepat terealisasi, subsidi Set Top Boxdari pemerintah sangat diharapkan, karena pesawat televisi penerima yang dimiliki oleh masyarakat masih banyak yang bersifat analog, sehingga belum dapat menerima siaran digital dan meringankan beban rakyat kecil karena untuk membeli pesawat DVB-T2 sangat mahal.

Pemerintah dapat memberikan pelatihan lanjutan baik di dalam negeri maupun diluar negeri, agar terwujud kemampuan SDM yang profesional, kreatif dalam menghasilkan siaran dan handal dalam pengolahan teknologi digital.Pemerintah memberikan sosialisasi secara langsung sampai ke pelosok-pelosok agar masyarakat mendengar, mengerti dan memahami secara langsung sistem siaran digital sehingga masyarakat dengan sendirinya terbuka dan tertarik ke sistem digitalisasi.

\section{Daftar Pustaka}

Ariansyah, K. (2014). Analisis interferensi T-DAB dan TV Analog pada pita Very High Frequency ( VHF ) Interference Analysis of T-DAB and Analog Television on VHF Band. Buletin Pos Dan Telekomunikasi,

$$
\text { 12(1), 217-230. }
$$

Budiman, A. (2015). Model Pengelolaan Digitalisasi Penyiaran di Indonesia (. In Politica (Vol. 6, Issue 2).

Digital Terrestrial Television Action Group. (2009). Understanding DVB-T2. DigiTAG.

Gultom, A. D. (2015). Kajian implementasi radio siaran digital di Indonesia (Study of digital radio broadcasting implementation in Indonesia). Buletin Pos Dan Telekomunikasi, 13(2), 133. https://doi.org/10.17933/ bpostel.2015.130203

Gultom, A. D. (2018). Digitalisasi Penyiaran Televisi di Indonesia. Buletin Pos Dan Telekomunikasi, 16(2), 91. https://doi. org/10.17933/bpostel.2018.160202

Jamroni. (2010). Perencanaan Strategi Penerapan Teknologi DVB-T di LPP TVRI. InComTech, Jurnal Telekomunikasi Dan Komputer, 1(2), 83-95.

Munadi, R., Walidainy, H., Irhamsyah, M., \& Hafidh, A. R. (2016). Kajian Kesiapan Transisi Sistem Televisi Analog ke Sistem Televisi Digital ( Studi Kasus di Banda Aceh ). Proceedings Seminar Nasional Teknik Elektro (FORTEI 2016), 136-142. https:// doi.org/10.15171/ijhpm.2015.71

Nuryanto, L. E. (2014). Mengenal Teknologi Televisi Digital. Orbith: Majalah Ilmiah Pengembangan Rekayasa Dan Sosial, 10(1), 29-36. https://doi.org/10.32497/ORBITH. V10I1.359

Prasetyo, S. B. (2013). Analisis Alternatif Implementasi Regulasi Sebagai Dampak Keterlambatan Analog Switch-Off (Aso) Terhadap Penyelenggaraan Penyiaran Televisi Pada Masa Simulcast. Universitas Mercu Buana.

Sari, D. (2015). Prospek Penyelenggaraan Penyiaran Digital. In M. . Rusadi, Dr. Udi, Drs. Djoko Waluyo, M.Si, Somo Arifianto S.E. (Ed.), Bunga Rampai : Infrasrtuktur TIK, Layanan Informasi dan Dinamika Sosial (1st ed., pp. 49-72). Pusat Litbang 
Penyelenggaraan Pos dan Informatika.

Setiawan, D. (2013). Pemodelan akselerasi implementasi Digital Dividend di Indonesia. In Universitas Indonesia. Universitas Indonesia.

Sugiyono. (2008). Metode Penelitian Bisnis. Alfabeta.

Sugiyono. (2017). Metode Penelitian Kuantitatif Kualitatif dan $R \& D$. Alfabeta.

Susanto, A., Sari, D., A, V. H., Prabowo, A., Adaniah, W. R., Mahmudah, D., Wardahnia, Dwiardi, A. R., Marselita, D., S., R. B., Tribroto, S., \& Purwaningsih, E. H. (2016). Buku Putih Komunikasi dan Informatika 2016. Puslitbang Sumber Daya, Perangkat
Dan Penyelenggaraan Pos Dan Informatika Badan Penelitian Dan Pengembangan Sumber Daya Manusia Kementerian Komunikasi Dan Informatika, 9. http://www. balitbangsdm.kominfo.go.id

Wahyudin,A., \& Sakinah, S. (2017). Perancangan dan Analisa Penggelaran Lte Pada Frekuensi 700 Mhz Dengan Metode Adaptif Modulation Coding Untuk Implementasi Digital Dividend di Wilayah Sub-Urban Dan Rural Kabupaten Banyumas. Jurnal Elektro Dan Telekomunikasi Terapan, 3(2). https:// doi.org/10.25124/jett.v3i2.303

Widjojo, D. A. (2013). Pemancar Televisi dan Peralatan Studio (1st ed.). Alfabeta. 